\title{
Quantitative evaluation system for tissue-engineered corneal epithelial cell sheets using image-based technology
}

\author{
Tamiyo Kobayashi' ${ }^{1}$, Masayuki Yamato², Teruo Okano² and Yuichi Watanabe ${ }^{1^{*}}$ \\ *Correspondence:yuichi_watanabe@ot.olympus.co.jp \\ 'Life Science Business Division, Olympus Corp., Shinjuku Monolith, 3-1 Nishi-Shinjuku 2-chome, Shinjuku, Tokyo 163-0914, \\ Japan. \\ 2Institute of Advanced Biomedical Engineering and Science, Tokyo Women's Medical University, 8-1 Kawada-cho, Shinjuku, Tokyo \\ 162-8666, Japan.
}

\begin{abstract}
Background: Tissue-engineered corneal epithelial cell sheets have been applied for treating ocular surface diseases. It is essential to establish a standardized validation system for fabricated cell sheets before transplantation to spread the therapy in the world. It has already been reported that a validation system for tissue-engineered corneal epithelial cell sheets was developed, in which several sliced frozen sections of sheet were fluorescently stained and the each was subjectively quantitated under a microscope with naked eye. In this study, we attempted a platform for an evaluation system which can be more simplified in preparation steps and more objective in quantification by automatically observing wider area of sample areas.

Methods: Human limbal epithelial cells isolated from corneoscleral rims of cadaveric donors $(n=4)$ were cultured with 3T3 feeder layer cells on a temperature-responsive culture insert for two different culture periods, for day 15 and 28 . The fabricated cell sheets, without slicing them, were fluorescently stained with five antibodies and with DAPI for nuclear staining, and then a wider area of the sheets were automatically scanned by a confocal microscope and quantitatively analyzed using a 2-D image processing technique with combination of two spatially-cropped images, lower and upper, which are created by dividing stacked image at the center of its z-direction.

$\underline{\text { Results: }}$ The cell sheets harvested on day 15 consisted of 4-6 layers of cells, the number of which in the lower was about 1.5 to 2.0 times larger, compared to that in the upper while on day 28 they had only 2-3 layers with the decreased number of cells by about $50 \%$ in the lower. The differences in the protein expressions the culture periods brought about were successfully quantitated by image processing technique as well. On day 15, ZO-1, AE5 and MUC16 were predominantly expressed in the upper while the expression of panCK was seen in every cell on the sheet. On day 28, the expression levels of ZO-1, AE5, MUC16 and panCK were decreased in the both layers with some unique features. Cells expressing p63 were predominantly observed in the basal layer of the sheets on day 15, but the level was decreased on day 28 as well.

Conclusions: The combinational image-based technology could be one of the powerful tools in establishing a standardized validation system not only for corneal treatment but for some other tissue-engineered ones.

Keywords: Tissue-engineered cell sheets, regenerative medicine, quantitative analysis, standardized system, image processing, confocal microscope
\end{abstract}

\section{Introduction}

Corneal epithelial stem cells are seen in the basal layer of transitional zone called limbus between the cornea and the bulbar conjunctiva [1]. They are responsible for renewal and restoration of the corneal epithelium by generating progeny (transient amplifying cells), which are committed to epithelial differentiation, with the capabilities of migrating into the corneal basal layer from the limbus $[2,3]$. Corneal opacification with severe visual impairment results from limbal disorder with complete loss of corneal epithelial stem cells caused by some severe trauma or eye diseases, where the peripheral conjunctival epithelium invades inwardly due to the lack of its sources of corneal epithelial cells, with its surface enveloped by vascularized conjunctival scar tissue $[4,5]$. Limbal allograft transplantation is commonly performed for patients with unilateral or bilateral limbal stem-cell deficiencies [6], which, however, can require long-term immunosuppression that involves high risks of serious eye and systemic complications [7].
Graft failure is often seen in patients with the Stevens-Johnson syndrome or ocular because of pemphigoid serious preoperative conditions such as persistent inflammation of the ocular surface, abnormal epithelial differentiation of the ocular surface, severe dry eyes, and lid-related abnormalities [7,8,9].

Several groups have recently reported that epithelial cell transplantation was really effective treatment for those suffering from these severe ocular surface diseases $[10,11,12]$. Nishida et al., also showed a regenerative therapy with transplantation of functional tissue-engineered epithelial cell sheets fabricated on a temperature-responsive culture dish, the surface of which is coated with polymers of poly $\mathrm{N}$-isopropylacrylamide (PIPAAm) which reversibly change its property of hydrophobic/hydrophilic depending on temperature across $32^{\circ} \mathrm{C}$, where the cultured cells can be easily harvested in a single form of contiguous cell sheet without using proteolytic enzymes like trypsin solution only by reducing temperature below $32^{\circ} \mathrm{C}[13,14]$.

Hayashi et al., have recently developed a validation system

(c) 2013 Watanabe et al; licensee Herbert Publications Ltd. This is an Open Access article distributed under the terms of Creative Commons Attribution License (http://creativecommons.org/licenses/by/3.0). This permits unrestricted use, distribution, and reproduction in any medium, provided the original work is properly cited. 
Kobayashi et al. Journal of Regenerative Medicine \& Tissue Engineering 2013,

to confirm whether or not a tissue-engineered epithelial cell sheet is transplantable in terms of the quality, considering that nobody has reported on how to validate final products for transplantation despite the fact that the corneal epithelial regenerative therapy, one of the most advanced applications of regenerative medicine, could be developed into one of the standard medical treatments from clinical trials [15]. Thinly sliced sections of cell sheets fluorescently-stained with four antibodies (not simultaneously but separately), p63 (stem/progenitor cells) [16], AE5 (differentiation), ZO-1 and MUC16 (barrier function) $[17,18]$ were observed under a microscope and subjectively evaluated with naked eye, while cells obtained by dispersing a part of the cell sheets were also stained with anti-panCK antibody (purity of epithelial cells) and quantitatively analyzed by flow cytometry [15].

Methodology with Image-based analysis has been increasingly developed especially to control cell quality for clinical cell therapy $[19,20]$. Kato et al., developed a nondestructive image-based system for cell quality assessment by applying their own unique algorithms without fluorescently staining cells [21]. Kim et al., developed a novel system to characterize spatial cell distribution in multilayer sheet of human keratinocytes in the proliferative and growtharrested states using a confocal laser scanning microscope in combination with image processing technology [22].

In this study, we attempted direct observation of the whole of cell sheets stained with the five antibodies (p63, AE5, ZO1, MUC16 and panCK), without preparing sliced sections of cell sheets, using a confocal laser scanning microscope and quantification with image processing technology what is called high content analysis, which allows quantitative image analyses by extracting information on spatial distribution of fluorescently-labeled components and providing statistical data, in order not only to reduce time-consuming multiple steps of preparing samples but also to fill gaps among researchers in qualitatively evaluating samples under the microscope with naked eye $[23,24]$. The methodology of automatically scanning samples makes it possible to observe much wider range of fields than the one of observing only a thinly-sliced section, which could provide more detailed and accurate information. We compared cell sheets between two different culture periods, for day 15 and 28 referring to the previous report [15], according to which, cells' density in a dish on day 10 was so low that they found it impossible to detach it as a cell sheet due to the short culture periods. On the other hand, they showed that cell sheets on day 15 (normal culture periods) and day 28 (excess culture periods) could be detached although some sheets on day $28 \mathrm{might}$ be detached partially-broken.

\section{Materials and methods Epithelial cell culture}

Human limbal tissues were isolated from corneoscleral rims of cadaveric donors (Northwest Lions Eye Bank, Seattle, WA).
The tissues were washed with Dulbecco's phosphate-buffered saline (Sigma-Aldrich, Canada, Ontario) containing antibiotics and antibacterias (Life Technologies Inc. Carlsbad, CA), and incubated with dispase II (3 U/ml) (Life Technologies Inc.) at $37^{\circ} \mathrm{C}$ for 1 hour in order to separate the epithelial layer. The layer was then treated with trypsin-ethylenediaminetetraacetic acid (EDTA) (Sigma-Aldrich) at $37^{\circ} \mathrm{C}$ for $10 \mathrm{~min}$. The cells were plated on temperature-responsive 6-well culture inserts (CellSeed, Tokyo, Japan) in KCM medium (Dulbecco's modified Eagle's medium (DMEM)/F12 [3:1]) supplemented with 10\% fetal bovine serum (Japan Bio Serum, Hiroshima, Japan), 0.5\% Insulin-Transferrin-Selenium (ITS; Life Technologies Inc.), 2.0 $\times 10^{-9} \mathrm{M}$ triiodothyronine (MP Biomedicals, Aurora, $\mathrm{OH}$ ), 0.4 $\mu \mathrm{g} / \mathrm{ml}$ hydrocortisone succinate (Wako, Osaka, Japan), 10 $\mathrm{ng} / \mathrm{ml}$ EGF (Life Technologies Inc.) and $1.0 \times 10^{-9} \mathrm{M}$ cholera toxin (Wako, Osaka, Japan), at 150,000 cells per insert where $\mathrm{NIH} / 3 \mathrm{~T} 3$ cells (ECACC, Salisbury, UK) treated with $10 \mu \mathrm{g} / \mathrm{ml}$ of mitomycin $\mathrm{C}$ have been prepared on the bottom plates.

\section{Antibodies}

In order to make multi-immunofluorescent staining of cell sheet possible, anti-cytokeratin $3 / 2 p$ mouse monoclonal antibody (AE5; PROGEN, Germany) was fluorescently labeled with Alexa Fluor 488 monoclonal antibody labeling kit (Life Technologies Inc.). Fluorescence conjugated antibodies, anti-ZO-1-Alexa Fluor 594 (mouse monoclonal; 1A12) and anti-pancytokeratin (panCK) -FITC (mouse monoclonal; Ks pan 1-8) were purchased from Life Technologies Inc. and PROGEN Biotechnik GmbH (Heidelberg, Germany), respectively. Anti-MUC16 antibody (mouse monoclonal; Ov185; AbCAM, Cambridge, UK) was labeled with Alexa Fluor 647 Zenon mouse IgG labeling kit (Life Technologies Inc) just before staining step. Rabbit anti-p63 polyclonal antibody was purchased from LIFESPAN (Seattle, WA).

\section{Immunofluorescence staining}

The fabricated cell sheets with trans-well membrane were cut away with the knife from its insert container along with the curve without detaching cell sheets from the membrane. They were fixed with cold methanol at $4^{\circ} \mathrm{C}$ for $10 \mathrm{~min}$. and washed with Tris-buffered saline (TBS; Takara Bio, Shiga, Japan). Cell sheet with membrane, which is helpful in cropping images because of its flatness, was bisected for immunofluorescence staining (Figure 1). One of the bisected cell sheets was incubated with group1 solution containing Alexa Fluor 488-conjugated anti-AE5 and Alexa Fluor 594-conjugated anti-ZO-1 antibodies, and the other was incubated with group2; FITC-conjugated anti-panCK, anti-p63 and Alexa Fluor 647-labeled anti-MUC16 antibodies in TBS-based staining buffer containing $5 \%$ donkey serum (Sigma-Aldrich) and $0.3 \%$ Triton X100 (Wako) for $40 \mathrm{~min}$. at room temperature, and washed twice with TBS-based washing buffer containing 0.05\% tween 20 (Affymetrix, Santa Clara, CA). The group 2 was additionally incubated with secondary antibody, Alexa Fluor 


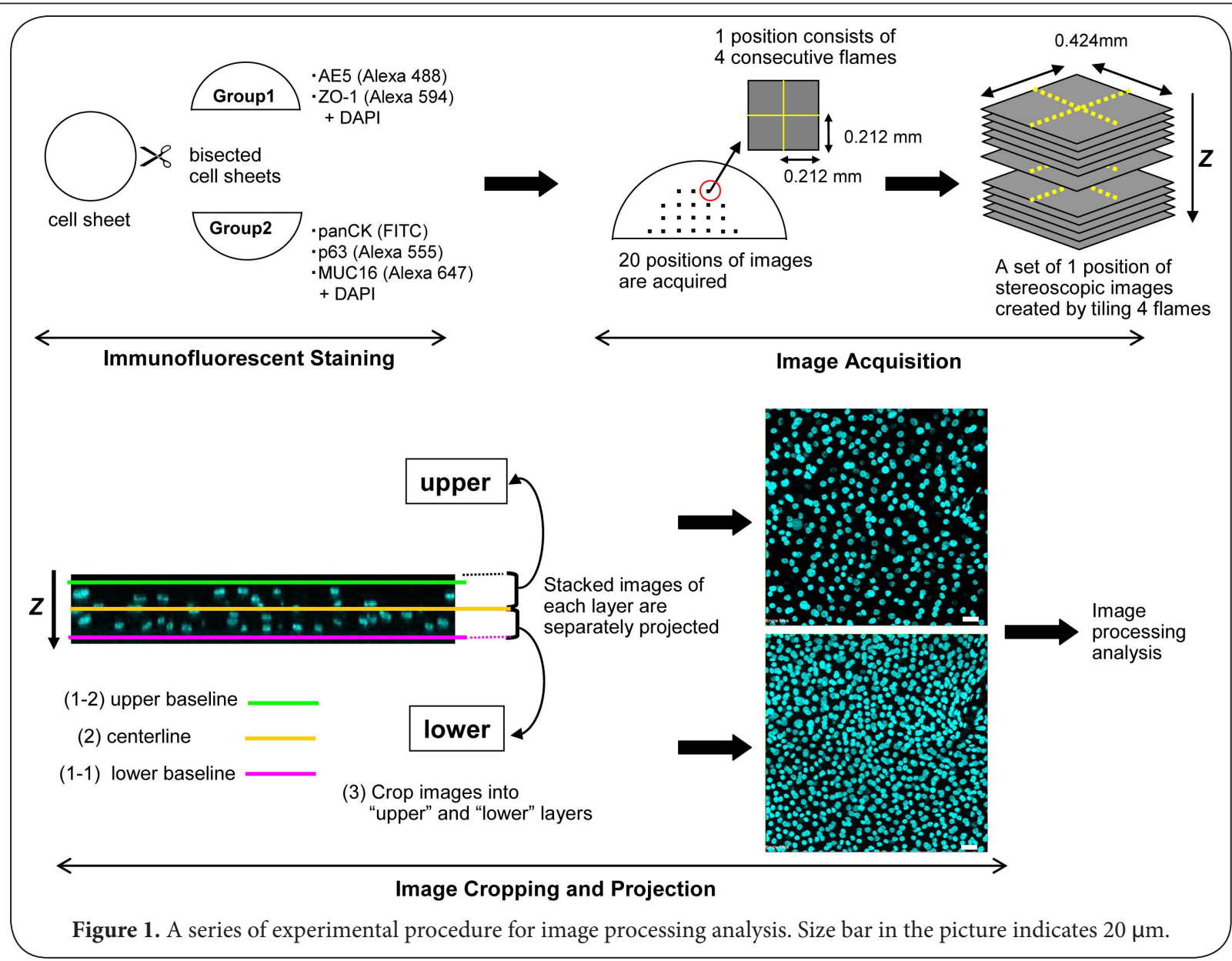

555 goat anti-rabbit IgG antibody (Life Technologies Inc.) for $20 \mathrm{~min}$. in the staining buffer. The both groups of the sheets were stained with $5 \mu \mathrm{g} / \mathrm{ml}$ of DAPI (Roche, Basel, Schweiz) for $5 \mathrm{~min}$. at room temperature, and then washed with the washing buffer three times and mounted on a slide glass with TBS. For negative controls, samples were also stained with their own isotype controls; Alexa Fluor 488 mouse lgG1 (Biolegend, San Diego, CA), Alexa Fluor 594 mouse lgG1 (Cell Signaling Technology, Danvers, MA), FITC mouse IgG2a (Santa Cruz Biotechnology, Santa Cruz, CA), polyclonal rabbit lgG (R\&D Systems, Minneapolis, MN) and normal mouse IgG1 (Santa Cruz Biotechnology, Santa Cruz, CA).

\section{Confocal laser scanning microscopy}

To acquire images of the fluorescently-stained cell sheets, we used the confocal laser scanning microscope FLUOVIEW (FV10i-W; OLYMPUS, Tokyo, Japan), which can scan a wide area of sample with motorized XY-stage automatically through $60 X$ objective lens. Fluorescence of DAPI, Alexa Fluor 488 (or FITC), Alexa Fluor 555 (or Alexa Fluor 594) and Alexa Fluor 647 were detected with its detector of Blue (420-460 nm), Green (490-540 nm), Red (570-670 nm) and Far-red (660-710 nm), respectively. The images from twenty positions per group of sample, in which four consecutive frames constitute one position of image, were taken at $1.0 \mu \mathrm{m}$ step in the z-direction (Figure 1).

\section{Image cropping and conversion}

Figure 1 indicates experimental procedure for Immunostaining and image acquisition to image processing analysis. The acquired four frames of images were tiled to constitute one position of image (XY: $424 \times 424 \mu \mathrm{m}$ ) and stacked in the form of three dimensions (XYZ). The 3-D stacked images were then spatially cropped at the center of the Z-direction into two layers of images, "lower" and "upper", with cellSens software (OLYMPUS, Tokyo, Japan), based on the positional information of DAPI-stained nuclei in the following procedure; (1) decide each baseline of the "lower" (1-1) and "upper" (1-2) at the point where no DAPI signal is detected in the image but it should be the closest image from the last DAPI-detectable one (usually 3 to $5 \mu \mathrm{ms}$ distance from the tip of the nucleus), (2) decide the Z-center position of the image by subtracting Z-value of the "upper" baseline" from the "lower" one, (3) crop the "lower" from the lower baseline to the centerline and then the "upper" from the centerline to the uppermost image beyond the upper baseline because some other 
(a) Nuclei
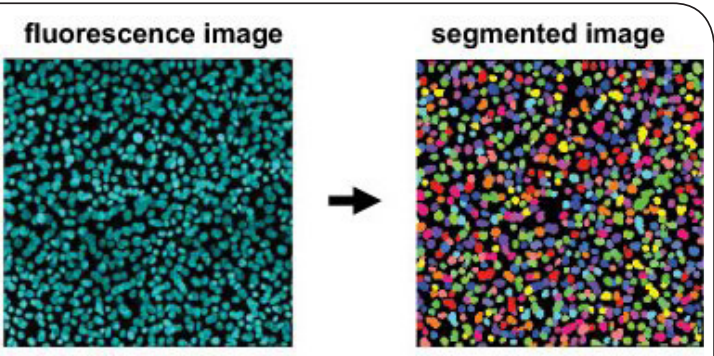

(b) ZO-1
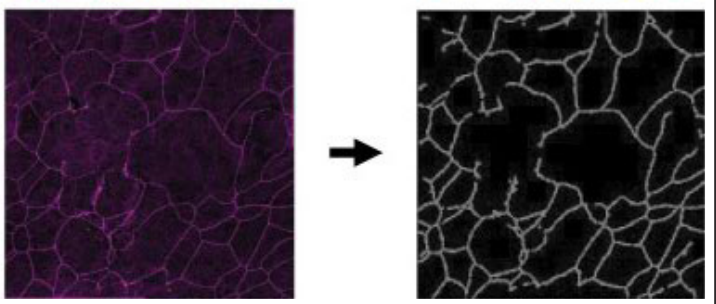

Figure 2. Segmentation of fluorescence images by image processing.

(a) Fluorescently stained nuclei of cells were segmented by image processing based on their shapes, morphology and brightness level. Detected nuclei are indicated as colored ones (upper right). (b) ZO-1 expression was detected by "string" module Traced ZO-1 signals are shown as gray lines in the picture (lower right).

signals except nuclear signal can be expressing beyond the upper baseline. The two spatially-cropped 3-D images were then projected separately into 2-D images. The projected images were quantitatively analyzed with CELAVIEW image processing software (RS100; OLYMPUS, Tokyo, Japan) $[25,26]$. The 3-D images were also reconstructed with Volocity image software (Perkin Elmer, Waltham, MA) to visually check them at different angles.

\section{Quantitative image analysis}

The forty projected images including "lower" and "upper" per group of sample were quantitatively analyzed with CELAVIEW software. Total fluorescent intensity per image was used to analyze expression levels of MUC16, AE5 and panCK. The number of the cells and their nuclear area (indicated by pixel) were automatically measured by object segmentation which can make several connecting DAPI-stained nuclei individually separated based on the threshold of their brightness, shapes and morphology (Figure 2a). Mean fluorescence intensity of Alexa Fluor 555-labeled p63 in the segregated nucleus was also quantitated at a single cell level. The expression level of ZO-1 was measured using a module with a unique algorism, "string", which is mainly used for detecting long and thin forms of objects such as neurites and angiogenesis tubule formation (Figure 2b).

\section{Results and discussion}

2-D Image processing technique with combination of two spatially-cropped images, lower and upper, which are created

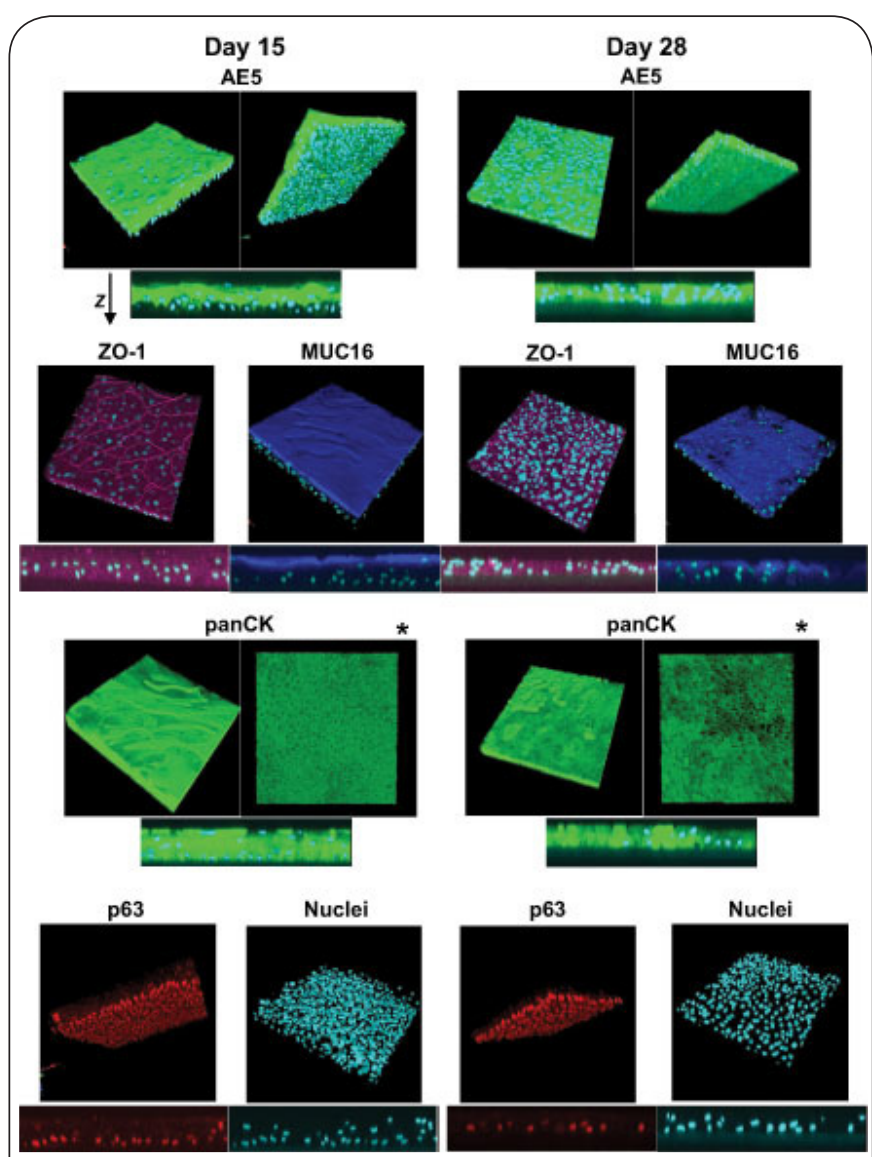

Figure 3. Representatives of $3-\mathrm{D}$ and $\mathrm{X}-\mathrm{Z}$ reconstructed images of cell sheets on day 15 and 28.

Cultured cell sheets were immunofluorescently stained with five antibodies; group1: AE5 (Alexa Fluor 488: green), ZO-1 (Alexa Fluor 594: magenta), group2: MUC16 (Alexa Fluor 647: blue), p63 (Alexa Fluor 555: red) and panCK (FITC: green), and the both groups were counterstained with DAPI (cyan) for nuclei.

* These two images of panCK are seen from the bottom of cell sheets.

by dividing stacked image at the center of its z-direction, successfully quantitated the fabricated epithelial cell sheets without directly analyzing the images of 3-D-reconstructed cell sheets. Figure 3 indicates the $3-D$ and $X-Z$ reconstructed images of the cultured corneal epithelial cell sheets on day 15 and 28, which were immunofluorescently stained with five antibodies and DAPI for nuclei. The projected images are also shown in Figure 4.

The epithelial cell sheets harvested on day 15 had 4-6 layers of the cells while those on day 28 looked thinner and fragile because of consisting of only 2-3 layers of cells as shown in Figure 3. As indicated in Figure 5, on day 15, the number of the cells counterstained with DAPI in the lower was about 1.5 to 2.0 times larger, compared to that in the upper layer (Figure 5a). It was, however, decreased by about $50 \%$ in the lower on day 28 (except sample 4). Corneal differentiated 


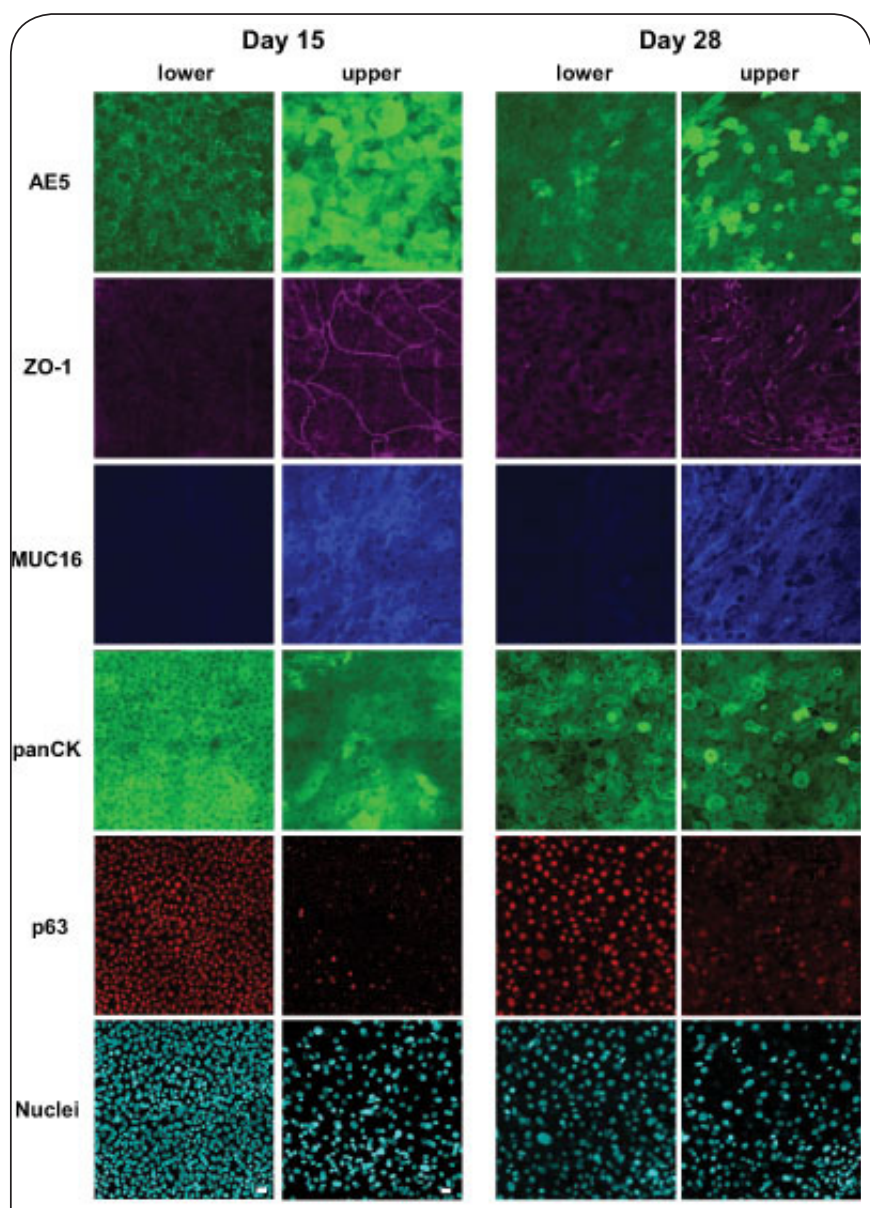

Figure 4. Representatives of projected images of "lower" and "upper" layers on day 15 and 28.

Size bar in the picture indicates $20 \mu \mathrm{m}$.

epithelial cell marker, AE5 (cytokeratin $3 / 2 p$ ), predominantly expressed in the sheet although its expression was very faint in the basal layer of the sheets, which was consistent with the results of quantitative image analysis. The AE5 expression level in the upper layer was about 1.4 to 1.9 times higher than the one in the lower (Figure 5c). As to pancytokeratin (panCK), one of the markers indicating purity of epithelial cell, little difference was seen between the lower and upper layer in the expression level although, compared to the upper layer, slight increase in its expression in the lower could be observed because of the larger number of the cells in the lower (Figure 5d). Membrane-associated mucin (MUC16), which is specifically seen on ocular surface where it plays an important role in epithelial barrier function, was continuously expressed throughout superficial cells as if it were covering the whole other cells in the lower layer. The MUC16 expression in the upper was over 5 times more than that in the lower (Figure 5e). The expression level of tight junction marker (ZO-1) detected with "string module" which recognizes a net-like structure (Figure $\mathbf{2 b}$ ), was about 6-9\% in the upper layer of images and below $1 \%$ in the lower (Figure 5f).
The cells expressing p63, stem/progenitor cells' marker, were predominantly in the lower layer (Figure 3), and over $50 \%$ of p63-positive cells in the cell sheet (lower + upper) were seen in the lower while the upper layer had below 25\% (Figure 5g). To confirm the expression of p63 in the lower and upper layers, the cells were visually shown by "image gallery", one of the most useful tools of CELAVIEW (Figure 6).

On the other hand, in the epithelial cell sheet harvested on day 28 , similar tendency could be observed in the five protein expression level in sample 1, 2 and 3 although sample 4 had very slight decreases or no changes in the expressions except that of $\mathrm{p} 63$ expression (Figure $\mathbf{5 g}$ ). The expression levels of AE5 panCK, ZO-1, MUC16 and p63 were decreased in the both lower and upper layers although these decreasing degrees varied depending on samples. Some round shaped cells with higher fluorescence intensity of AE 5 and panCK were mainly seen in the upper layers. The signal of ZO-1 was disconnected and faint in almost all the upper layers $(<2 \%)$ as shown in Figure 3 and Figure 4, while the ZO-1 net-like structure was little detected in the lower layer as well as on day $15(<1 \%)$. The loss of MUC16 signal or its "cave-in" in the surface of the cell sheets on day 28 , which sometimes contributes to increase in MUC16 signal in the lower layer, was observed in some parts of the cell sheet where contiguous MUC16 expression must have been seen throughout superficial cells on day 15 although the damaged level of the cell sheets greatly varied among samples.

Additionally, we also analyzed the cell sheets on nuclear area of the cells stained with DAPI by randomly selecting 2000 cells per each layer. On day 15 , the average of the nuclear area in the upper (approx. 500 pixels) was 1.5 times larger than that of the lower (approx. 800 pixels) (Figure 5b). More interestingly, cells with larger nuclear area were primarily detected in the lower on day 28 (Figure 4 and Figure 5g).

In this study, we analyzed two cropped and projected images, "lower" and "upper", using the 2-D image processing software to obtain statistical results rapidly, not with stereoscopic methodology which is impractical at present to statistically process massive amounts of 3-D images although it can directly analyze 3-D images. Spatial division of 3-D image at the center of the Z-position into two 2-D images enables us to successfully represent prominent features of the bottom layer and superficial layer in corneal epithelial cell sheets. In addition, all the images were taken with high transparent insert membrane without detaching it so as to hold flatness of bottom layer constant for image cropping and also avoid further damages of cell sheets especially harvested on day 28.

On day 15 , we successfully obtained the stable results that all of the four samples showed similar values in each protein expression, the number and the nuclear area of the cells with a certain level of the ratio (lower/upper). More importantly, little differences among 20 positions of the acquired images per group of sample were seen in the parameters (Figure 7, 


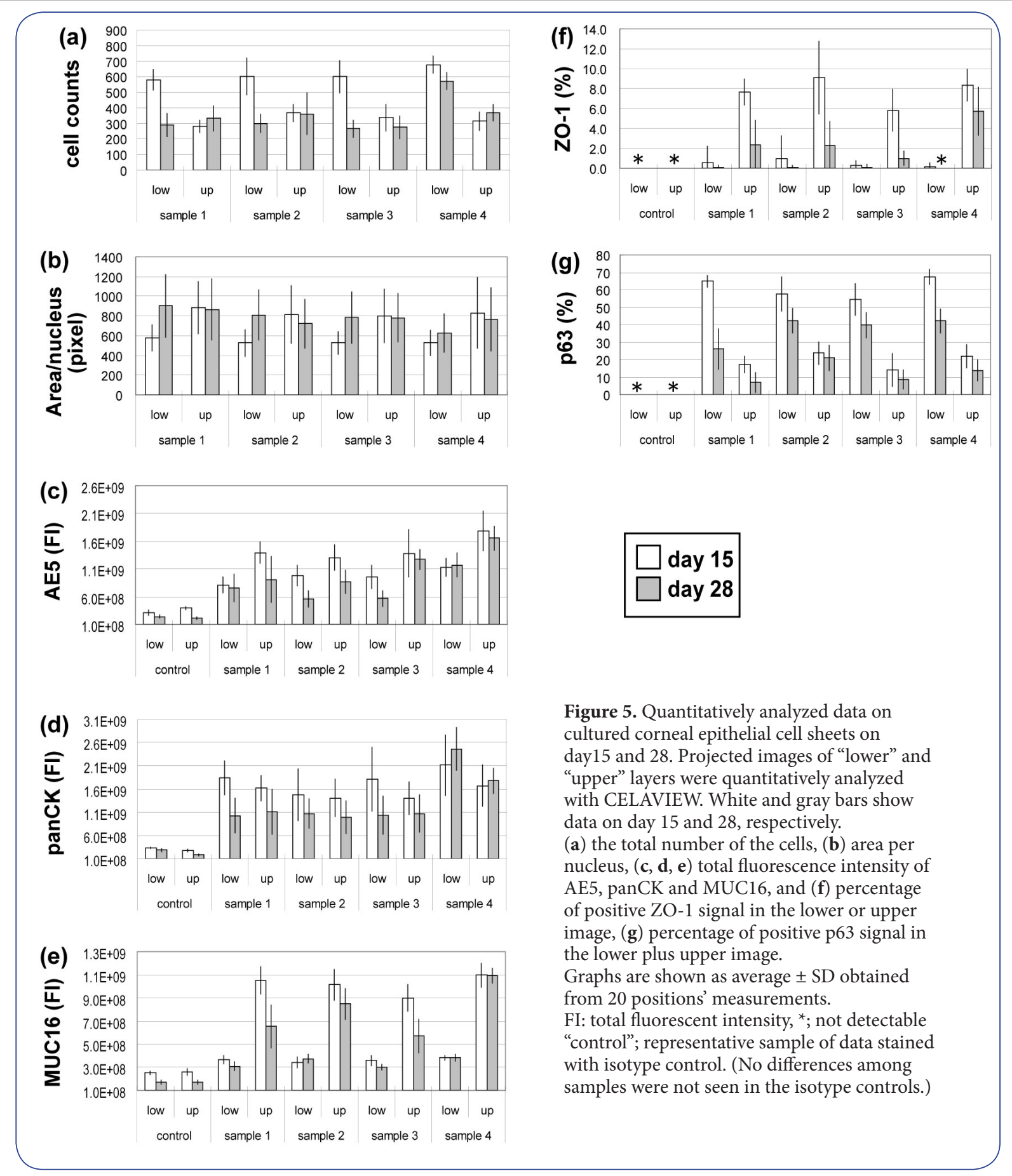

day 15), which indicates that cell sheets harvested on day 15 consist of stable and uniform cell layers so that they can form a population when shown in scatter plot of the parameters. On day 28, the level of the protein expression in sample 1, 2 and 3 tended to be declined in accordance with the decreased number of the cells although the values varied depending on positions of the sheets so that the scatter plot on day 28 tended to scatter downward (Figure 7, day 28).

As to the sample 4 on day 28 , it didn't have any damages the other three samples had on day 28 in their cell sheets, and the rise in some proteins' expression, far from being the decline, could be seen. We don't know the reason for little or no change in the parameters of the sample 4 because each sample used in this study had different conditions in the elapsed time (from death to surgical removal of eyeball, from removal to the start of stem cell culture) and in the delivery from Seattle in the USA to Tokyo in Japan, to say nothing of the genetic background. 


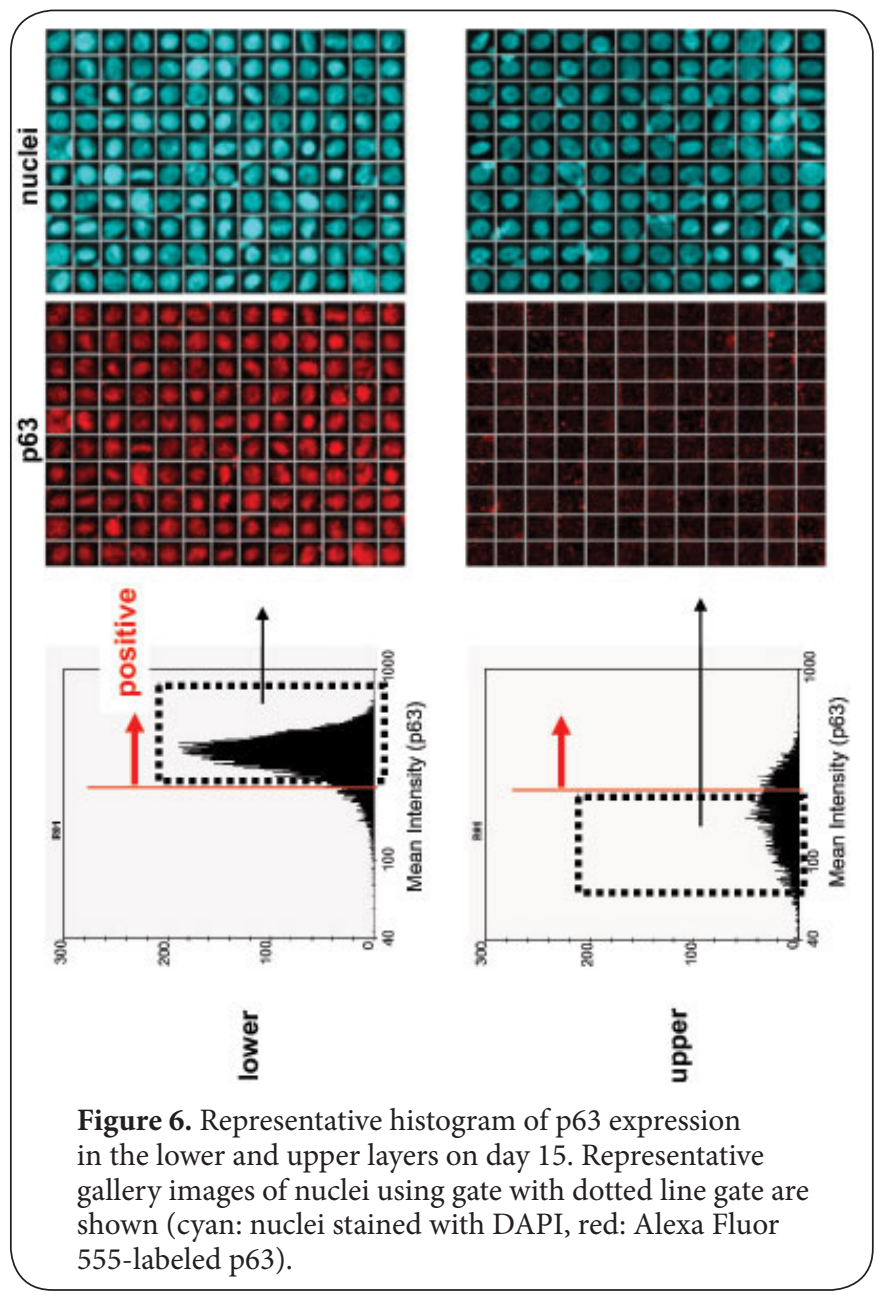

We also demonstrated that analysis of nuclear area of the cells showed outstanding difference in size between the lower and the upper layer. This difference may possibly be another new parameter for evaluating cell sheets. It would be essential to standardize an evaluation system in order to spread some treatments with regenerative medicine into the world, and it could be also accelerated by a rapid, objective and statistical quantification system in combination with interactive function of the software between visual images and its numerical data as indicated by "image gallery" in Figure 6 [26].

\section{Conclusion}

We were successfully able to evaluate the differences in the protein expressions the culture periods brought about by using combination of the confocal laser scanning microscope and image processing technology. The microscope has made it possible to directly observe tissue-engineered corneal epithelial cell sheets without preparing thinly-sliced sections, which requires time-consuming process and skilled technique, not to mention the fact that it can automatically scan a wider range of areas or positions of cell sheets. Observation of multicolor-stained cell sheets allows us not only to save time
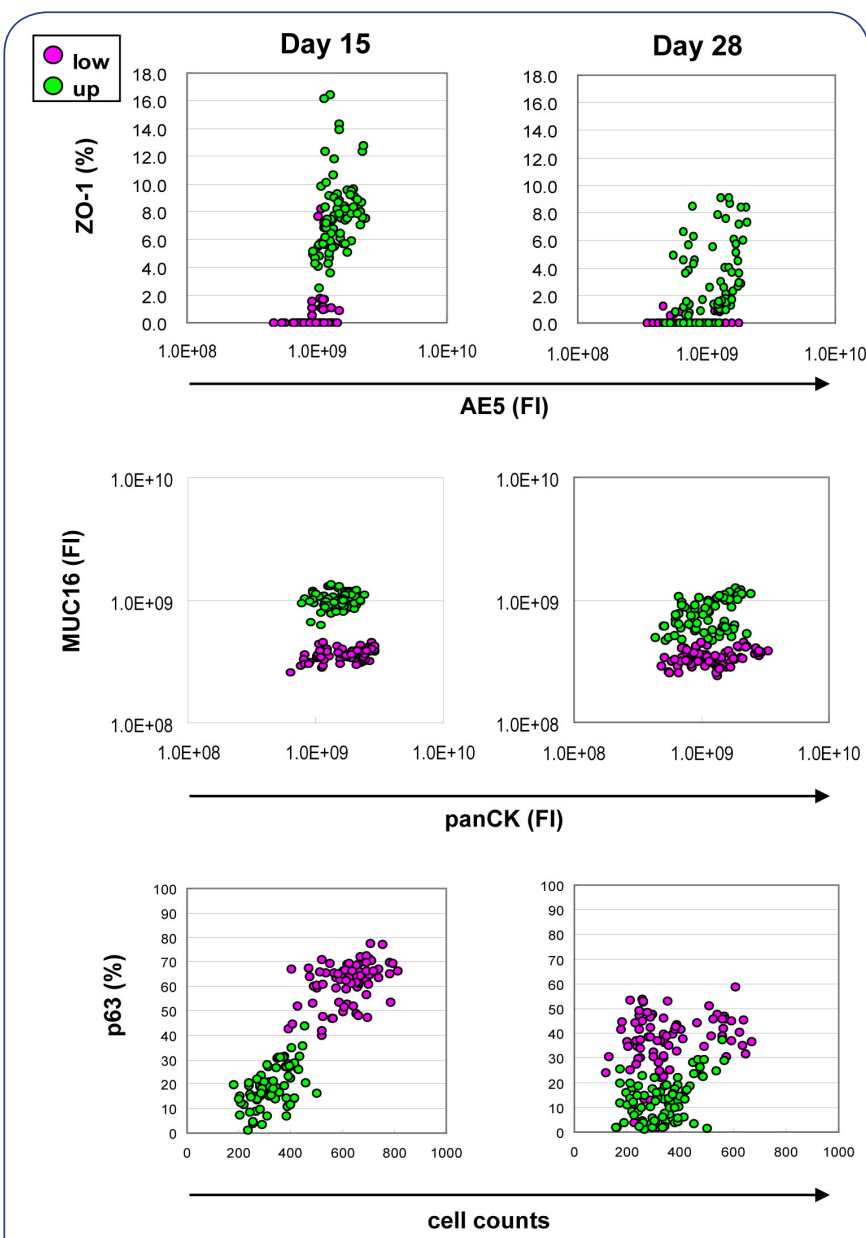

Figure 7. Scatter plots obtained from the four samples on day 15 and 28. Each sample has 20 positions of images, where each image consists of the lower and upper layers. Green and pink dots show values from the upper and lower layers, respectively. Each dot indicates the total fluorescent intensity (AE5, panCK and MUC16), the percentage of positive signal (ZO-1 and p63) and cell counts per lower or upper image.

FI: total fluorescent intensity.

and labor but also to get multi-information of parameters from exactly the same sample at the same time. Moreover, objective and statistical quantification of cell sheets by the image processing technique which allows analyzing data under the same conditions, no matter who may do it, can reduce human-error and minimize deviation between individuals, compared to subjective one under the microscope through the eyepieces with naked eye.

Comprehensive combinational study of "quantitative evaluation before transplantation" and "clinical tests' results after transplantation" would be needed to create a specific and appropriate validation standard system for transplantation of corneal epithelial cell sheets. This image-based technique must be helpful for evaluating some other cell sheets. Kim et al., evaluated early-stage maturation of human retinal pigment epithelial cells to semi-quantitatively analyze the formation of 
ZO-1 tight junction and judge the stratification by counting total and overlapping nuclei [27], which might give some hints to quantitatively analyze stratification we did not do with image processing in this study.

All told, quantitative evaluation system based on imaging technique, sometimes providing far more information than expected, would be a powerful tool in establishing a validation standard before transplantation for regenerative medicine although this study is just an example to show how useful combinational image-based technology is.

\section{Competing interests}

Tamiyo Kobayashi submitted a patent application entitled "Evaluation method for cells with multi-layer structure using imaging technology (Appl. No.195938) on September 6, 2012.

\section{Authors' contributions}

T. Kobayashi was responsible for conception, design, execution, interpretation and preparing the manuscript of this study. M. Yamato and T. Okano provided advice on fabrication methods of corneal epithelial cell sheets, assays, interpretation of results and the manuscript. Y. Watanabe assisted in all aspects of this study mentioned above and interpretation of data. All authors have had the opportunity to provide manuscript revisions and they have approved the final version.

\section{Acknowledgement and funding}

We thank T. Fukuda (Japanese Consultant, Sight Life) for arrangement for the import of human cornea from Northwest Lions Eye Bank in the USA, and M Kondo, K Sumako (Waseda University) and H Sugiyama (Cell Seed Inc.) for technical advice for cell culture. This study was partially supported by Creation of innovation centers for advanced interdisciplinary research areas Program in the Project for Developing Innovation Systems "Cell Sheet Tissue Engineering Center (CSTEC)" from the Ministry of Education, Culture, Sports, Science and Technology (MEXT), Japan.

\section{Publication history}

Received: 01-Apr-2013 Revised: 06-May-2013

Accepted: 28-May-2013 Published: 07-Jun-2013

\section{References}

1. Schermer A, Galvin S and Sun TT: Differentiation-related expression of a major $64 \mathrm{~K}$ corneal keratin in vivo and in culture suggests limbal location of corneal epithelial stem cells. J Cell Biol 1986, 103:49-62. | Article | PubMed Abstract | PubMed Full Text

2. Cotsarelis G, Cheng SZ, Dong G, Sun TT and Lavker RM: Existence of slow-cycling limbal epithelial basal cells that can be preferentially stimulated to proliferate: implications on epithelial stem cells. Cell 1989, 57:201-9. | Article | PubMed

3. Lavker RM and Sun TT: Epidermal stem cells: properties, markers, and location. Proc Natl Acad Sci U S A 2000, 97:13473-5. | Article I PubMed Abstract | PubMed Full Text

4. Tseng SC: Concept and application of limbal stem cells. Eye (Lond) 1989, 3 ( Pt 2):141-57. | Article | PubMed

5. Nishida K: Tissue engineering of the cornea. Cornea 2003, 22:S28-34. | Article I PubMed

6. Tsubota K, Satake Y, Kaido M, Shinozaki N, Shimmura S, Bissen-Miyajima $\mathrm{H}$ and Shimazaki J: Treatment of severe ocular-surface disorders with corneal epithelial stem-cell transplantation. N Engl J Med 1999, 340:1697-703. | Article | PubMed

7. Samson CM, Nduaguba C, Baltatzis S and Foster CS: Limbal stem cell transplantation in chronic inflammatory eye disease. Ophthalmology 2002, 109:862-8. | Article | PubMed
8. Ilari L and Daya SM: Long-term outcomes of keratolimbal allograft for the treatment of severe ocular surface disorders. Ophthalmology 2002, 109:1278-84. | Article | PubMed

9. Shimazaki J, Shimmura S, Fujishima H and Tsubota K: Association of preoperative tear function with surgical outcome in severe StevensJohnson syndrome. Ophthalmology 2000, 107:1518-23. | Article | PubMed

10. Pellegrini G, Traverso CE, Franzi AT, Zingirian M, Cancedda R and De Luca $\mathrm{M}$ : Long-term restoration of damaged corneal surfaces with autologous cultivated corneal epithelium. Lancet 1997, 349:990-3. | Article | PubMed

11. Tsai RJ, Li LM and Chen JK: Reconstruction of damaged corneas by transplantation of autologous limbal epithelial cells. N Engl J Med 2000, 343:86-93. | Article | PubMed

12. Rama P, Bonini S, Lambiase A, Golisano O, Paterna P, De Luca M and Pellegrini G: Autologous fibrin-cultured limbal stem cells permanently restore the corneal surface of patients with total limbal stem cell deficiency. Transplantation 2001, 72:1478-85. | Article | PubMed

13. Nishida K, Yamato M, Hayashida Y, Watanabe K, Maeda N, Watanabe H, Yamamoto K, Nagai S, Kikuchi A, Tano $Y$ and Okano T: Functional bioengineered corneal epithelial sheet grafts from corneal stem cells expanded ex vivo on a temperature-responsive cell culture surface. Transplantation 2004, 77:379-85. | Article | PubMed

14. Nishida K, Yamato M, Hayashida Y, Watanabe K, Yamamoto K, Adachi E, Nagai S, Kikuchi A, Maeda N, Watanabe H, Okano T and Tano Y: Corneal reconstruction with tissue-engineered cell sheets composed of autologous oral mucosal epithelium. N Engl J Med 2004, 351:1187-96. | Article I PubMed

15. Hayashi R, Yamato M, Takayanagi H, Oie Y, Kubota A, Hori Y, Okano T and Nishida K: Validation system of tissue-engineered epithelial cell sheets for corneal regenerative medicine. Tissue Eng Part C Methods 2010, 16:553-60. | Article | PubMed

16. Pellegrini G, Dellambra E, Golisano O, Martinelli E, Fantozzi I, Bondanza S, Ponzin D, McKeon F and De Luca M: p63 identifies keratinocyte stem cells. Proc Natl Acad Sci U S A 2001, 98:3156-61. I Article I PubMed Abstract | PubMed Full Text

17. Hayashida $Y$, Nishida K, Yamato M, Watanabe K, Maeda N, Watanabe $\mathrm{H}$, Kikuchi $\mathrm{A}$, Okano $\mathrm{T}$ and Tano $\mathrm{Y}$ : Ocular surface reconstruction using autologous rabbit oral mucosal epithelial sheets fabricated ex vivo on a temperature-responsive culture surface. Invest Ophthalmol Vis Sci 2005, 46:1632-9. | Article | PubMed

18. Hori Y, Sugiyama H, Soma T and Nishida K: Expression of membraneassociated mucins in cultivated human oral mucosal epithelial cells. Cornea 2007, 26:S65-9. | Article | PubMed

19. Baradez $\mathrm{MO}$ and Marshall $\mathrm{D}$ : The use of multidimensional image-based analysis to accurately monitor cell growth in 3D bioreactor culture. PLoS One 2011, 6:e26104. | Article | PubMed Abstract | PubMed Full Text

20. Kino-Oka M, Maeda Y, Sato Y, Maruyama N, Takezawa Y, Khoshfetrat AB, Sugawara K and Taya M: Morphological evaluation of chondrogenic potency in passaged cell populations. J Biosci Bioeng 2009, 107:544-51. | Article | PubMed

21. Sasaki H, Matsuoka F, Yamamoto W, Kojima K, Honda H, Kato R: ImageBased Cell Quality Assessment: Modeling of Cell Morphology and Quality for Clinical Cell Therapy. Studies in Mechanobio, Tissue Eng and Biomat 2013, 10:207-226. | Article

22. Kim MH, Sonoi R, Yamada K, Inamori M and Kino-oka M: Analysis of locality of early-stage maturation in confluent state of human retinal pigment epithelial cells. J Biosci Bioeng 2012, 113:778-81. | Article | PubMed

23. Joanidopoulos K: Cell-based genome-wide RNAi screening with the new scan^R Screening Station. Nature Methods Application Notes 2006, an29. I Pdf

24. Neumann B, Held M, Liebel U, Erfle H, Rogers P, Pepperkok R and Ellenberg J: High-throughput RNAi screening by time-lapse imaging of live human cells. Nat Methods 2006, 3:385-90. | Article I PubMed

25. Obara Y, Yamauchi A, Takehara S, Nemoto W, Takahashi M, Stork PJ and 
Kobayashi et al. Journal of Regenerative Medicine \& Tissue Engineering 2013, http://www.hoajonline.com/journals/pdf/2050-1218-2-2.pdf

Nakahata N: ERK5 activity is required for nerve growth factor-induced neurite outgrowth and stabilization of tyrosine hydroxylase in PC12 cells. J Biol Chem 2009, 284:23564-73. | Article | PubMed Abstract | PubMed Full Text

26. Sakaue-Sawano A, Kobayashi T, Ohtawa K and Miyawaki A: Druginduced cell cycle modulation leading to cell-cycle arrest, nuclear mis-segregation, or endoreplication. BMC Cell Biol 2011, 12:2. | Article | PubMed Abstract I PubMed Full Text

27. Kim MH, Tsubakino N, Kagita S, Taya M and Kino-oka M: Characterization of spatial cell distribution in multilayer sheet of human keratinocytes through a stereoscopic cell imaging system. J Biosci Bioeng 2011, 112:289-91. | Article | PubMed

\section{Citation:}

Kobayashi T, Yamato M, Okano T and Watanabe Y: Quantitative evaluation system for tissue-engineered corneal epithelial cell sheets using image-based technology. journal of Regenerative Medicine and Tissue Engineering 2013, 2:2.

http://dx.doi.org/10.7243/2050-1218-2-2 